\title{
Exploring antecedents of attitude and intention toward Internet piracy among college students in South Korea
}

\author{
Hyoungkoo Khang • Eyun-Jung Ki • In-Kon Park • \\ Seon-Gi Baek
}

Received: 26 September 2011 / Accepted: 31 January 2012 / Published online: 22 February 2012

(C) Springer Science+Business Media B.V. 2012

\begin{abstract}
This study aims to examine the predictors of attitude and intentions toward Internet piracy in South Korea. Also, it intends to suggest a model of Internet piracy demonstrating the casual effects of factors of individual attitude and intentions toward Internet piracy. The results demonstrated that moral obligations and subjective norms are significant predictors of an individual's attitude toward Internet piracy. Moreover, three factors - moral obligation, perceived behavioral control, and attitudeare essential antecedents of an individual's intention to engage in Internet piracy. The findings of this study embrace multiple implications for factors affecting piracy and promote future research around this topic.
\end{abstract}

Keywords Internet piracy $\cdot$ South Korea $\cdot$ Attitude $\cdot$ Intention

Although new technology has positively advanced both our individual lives and society as a whole, such advancements are not without drawbacks. Due to fast Internet connections, the availability of affordable high capacity storage, and underground Internet peer-to-peer networks, the replication and distribution of products or services without the permission of copyright owners is now easier and faster than ever before (Cronan and Al-Rafee 2008). Moreover, diverse mobile devices including

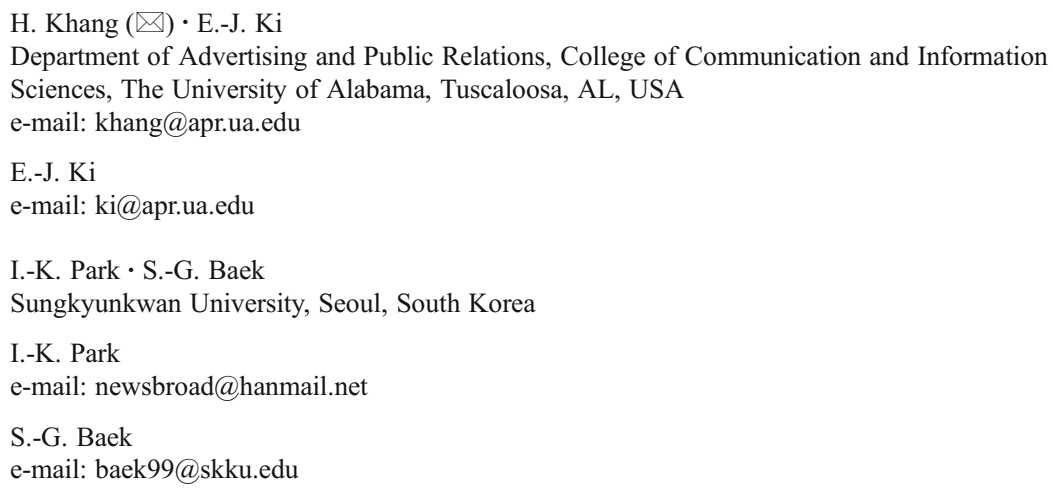


cellular phones, palm devices, and flash drives have contributed to the ubiquity of piracy (United States Trade Representative 2010).

The impacts of Internet piracy ${ }^{1}$ have become significant. For example, in 2008, over $40 \%$ of the personal computer software used worldwide was unauthorized, resulting in revenue losses surpassing the $\$ 50$ billion mark for the first time (Business Software 2010). Similarly, one in every three music CDs and cassettes sold worldwide is pirated, and the estimated value of the pirated music market in 2005 was at least $\$ 4.5$ billion (IFPI06 2006). Moreover, the Motion Picture Association of America estimated that in the same year, approximately a half million movies were copied and downloaded on the Internet everyday (MPAA 2005), which translated to an $\$ 18.2$ billion loss to the worldwide movie industry in 2005 .

In response to these issues, multiple organizations have been attempting to combat Internet piracy. For example, the Motion Picture Association of America (MPAA) has investigated more than 34,000 cases of piracy and assisted law enforcement officials in conducting more than 10,500 raids. The MPAA has also launched a global publicity campaign to emphasize their message that piracy is a crime and to increase public awareness of piracy activities.

While creative producers and related organizations have made efforts to fight Internet piracy, scholars have endeavored to identify determinants of piracy behaviors acting on individual (Al-Rafee and Cronan 2006; Chiou et al. 2005; Cronan and AlRafee 2008) and cross-cultural levels (e.g., Ki et al. 2006; Swinyard et al. 1990). Despite the magnitude of the problem, however, there has been relatively little research done to examine predictors of an individual's engagement in Internet piracy on a local level. In fact, Internet piracy has been a significant concern in a number of countries, including Brazil, Canada, China, India, Italy, Russia, Spain, and Ukraine (U.S. Trade Representative 2010).

South Korea, in particular, stands out as an interesting country to explore the issue of Internet piracy, since the country provides the fastest Internet connections in the world (McDonald 2011) and has been identified as a notorious market where numerous webhards $^{2}$ operate in Korean Web space to provide illegal content (U.S. Trade Representative 2010). In addition, South Korea is the country with the highest rate of Internet penetration in the world, reaching $81.1 \%$, though only 39.4 million people in the country use the Internet (Internet World 2010). This study specifically examines determinants of individual decision making pertaining to Internet piracy in South Korea.

In the Korean local context, this study aims to examine predictors of attitude and intentions toward Internet piracy. To achieve the objective, this study adopted varied antecedents of Internet piracy from previous studies that applied theories of planned behavior or reasoned action with additional variables (e.g., demographics, moral obligations (MO), perceived prosecution risk (PPR), etc.) to predict a wide range of immoral behaviors (e.g., Beck and Ajzen 1991; Cronan and Al-Rafee 2008). With those predictors identified, this study intends to suggest a model of Internet piracy demonstrating the casual effects of factors of individual attitude and intentions toward

\footnotetext{
${ }^{1}$ In this study, Internet piracy refers to any behavior involving illegal copying and/or distribution of copyrighted media such as software, movies, music, television programs, book files, etc. over the Internet without the copyright owner's permission.

${ }^{2}$ Webhards are web-based storage services that offer high-volume storage space for sharing of pirated material.
} 
Internet piracy. The findings of this study are expected to provide a better understanding of such factors on a local level. In addition, findings will inform the development of strategic decision making and the creation of effective persuasive messages for a public campaign to protect copyrights and intellectual property.

\section{Theoretical backgrounds}

\section{Theory of planned behavior}

The theory of planned behavior has been employed in studies examining factors affecting behavioral intention. This theory posits that three independent variables - attitude, subjective norm, perceived behavioral control-determine intentions toward the behavior in question (Ajzen 1991). It maintains, in particular, that all these variables are positively associated with behavioral intention. That is, the more favorable the attitude and subjective norm toward a behavior and the greater the perceived behavioral control, the stronger an individual's intention will be to engage in the behavior in question. Though theory of planned behavior (TPB) has garnered significant empirical evidence supporting the theory, still relatively less research has drawn upon this theory as compared to its predecessor, the theory of reasoned action (TRA). For example, Ajzen (1991) reviewed 16 studies that applied TPB and confirmed the sufficient predictive power of the model. Also, Parker et al. (1992) used both TRA and TPB to predict driving violations and determined that the addition of perceived behavior control (PBC) significantly increased the amount of variance explained. Based primarily on TPB and drawing upon several predictors identified in previous literature (Ajzen 1991; Cronan and Al-Rafee 2008; Parker et al. 1992), the present research examines the effects of six variablesgender, moral obligations, subjective norms, attitude, perceived behavior control, and perceived prosecution risk — on individuals' intentions toward Internet piracy.

\section{Gender}

Gender has been tested as a predictor of immoral behaviors such as piracy, though findings remain indecisive regarding its impact. A group of studies have reported that gender does little to explain immoral behaviors (e.g., Taylor and Shim 1993; Wong et al. 1990. For example, Taylor and Shim (1993) examined the effect of gender on software piracy and found no relationship between the two variables. In contrast, multiple studies have argued that gender represents a meaningful predictor of ethical behavior (e.g., Leonard and Cronan 2001; Reiss and Mitra 1998; Simpson et al. 1994). For example, Simpson et al. (1994) indicated that gender is an important variable influencing individuals' propensity toward partaking in software piracy. In studies that identified gender as a significant predictor, females generally demonstrated greater sensitivity to unethical activities than males (Ford and Richardson 1994; Pereira and Kanekar 1994). Computer use tends to be considered a masculine activity, and male students are generally more passionate about computers and spend more time using computers than their female counterparts do (Williams et al. 1994). This substantial use of computers by males may increase the likelihood of engaging in piracy activities. 
Gender and moral obligation MO is defined as the degree to which an individual feels guilt or a personal obligation to either engage in or refrain from performing an act. In general, individuals with higher levels of guilt tend to exhibit lower obligation regarding the behavior in question (Cronan and Al-Rafee 2008). As several studies have reported that females appear to be more sensitive to unethical acts than their male counterparts (Ford and Richardson 1994; Leonard and Cronan 2001; Reiss and Mitra 1998; Simpson et al. 1994), it is reasonable to assume that females might feel greater guilt and higher levels of moral obligation toward Internet piracy. Because the relationship between gender and moral obligation has rarely been tested, this study specifically examines this relationship and proposes the following hypothesis:

Hypothesis 1: Females will demonstrate higher levels of moral obligation than males.

Gender and attitude As females tend to demonstrate higher ethical standards than males, gender could play an important role in explaining individuals' attitudes toward immoral activities, such as Internet piracy in this study. For example, female students have been found to be more sensitive to the consequences of software piracy activity and as such demonstrate more negative attitudes toward such activities (Ang and Lo 1998; Sims et al. 1996). Applying findings from previous software piracy studies, this study proposes the following hypothesis:

Hypothesis 2: Females will possess more negative attitudes toward Internet piracy than males.

\section{Moral obligation}

Moral obligation and attitude An individual's moral judgment has been reported as an important precursor in determining his/her attitude toward activities that involve ethical decision making (Jones 1991). Individuals with higher levels of moral judgment are less likely to approve of or engage in immoral activities such as piracy (Rest 1979). Consequently, moral obligation is considered to impact an individual's attitude toward Internet piracy, thus contributing to the following hypothesis:

Hypothesis 3: Individuals with higher levels of moral obligation will demonstrate more negative attitudes toward Internet piracy.

Moral obligation and behavioral intention Moral obligation posits that an individual possesses a moral disposition that influences his/her actions. Feelings of guilt in effect serve to control behavior by inhibiting unethical actions (Grasmick and Scott 1982). Based on this rationale, studies in ethics have tested and reported moral obligation as an essential predictor of ethical behavioral intention (Banerjee and Cronan 1998; Conner and Armitage 1998; Cronan and Al-Rafee 2008; Leonard and Cronan 2001). Beck and Ajzen (1991) argued that integrating moral obligation into the TPB model could improve the model's overall predictive power, particularly for explaining the ethical decision-making process. In a similar vein, when considering the Internet piracy situation, it is reasonable to assume that an individual anticipating more guilt 
as a result of performing an unethical behavior will be less likely to demonstrate intentions of performing that behavior than an individual with less guilt anticipation. Therefore, the following hypothesis is proposed:

Hypothesis 4: Individuals with higher levels of moral obligation will demonstrate less intention of participating in Internet piracy.

\section{Subjective norms}

Subjective norms and attitude The subjective norm represents an individual's perceptions of what significant others such as peer groups in his/her life believe s/he should or should not do with regard to specific behaviors (Ajzen 1985). By applying this definition, this study conceptualizes subjective norms as one's perceptions of social pressure to participate or not participate in Internet piracy activity. Studies have found that one's attitude toward a certain action is more likely to be affected by his/ her significant others (e.g., Chang 1998; Bommer and Gratto 1987; Kreie and Cronan 1999). As subjective norms and attitudes are positively related, this study assumes that individuals whose significant others express more unfavorable opinions toward Internet piracy activity will possess a more negative attitude toward the behavior as well. Therefore, this study proposes the following hypothesis:

Hypothesis 5: Individuals with higher levels of subjective norms (not to perform the Internet piracy) will demonstrate more negative attitudes toward Internet piracy.

Subjective norms and intention TPB theorizes that subjective norms can explain one's intention for performing certain behaviors. Applying this notion, studies have confirmed the strong association between subjective norms and intentions to perform certain behaviors (e.g., Chang 1998; Peace et al. 2003; Vallerand and Pelletier 1992). For example, Peace et al. (2003) established a model to explain the intentions toward software piracy based on TPB and discovered that subjective norms act as important precursors of intention. Based on the theoretical assumption and evidence from existing studies, this study proposed the following hypothesis:

Hypothesis 6: Individuals with higher levels of subjective norms (not to perform the Internet piracy) will demonstrate less intention of participating in Internet piracy.

\section{Perceived behavior control}

This variable explains one's perception of ease or difficulty of performing a behavior based on his/her ability (Ajzen 1991). TPB postulates that PBC could be a direct and more important predictor of behavior intention than subjective norms or attitude. Even if one's subjective norms and attitudes do not favor engagement in a certain act, PBC explains the issue of ability to perform the behavior. In other words, when individuals perceive themselves as having greater ability or control in piracy 
situations, they will be more likely to engage in piracy behaviors regardless of subjective norms or attitudes. In particular, individuals with greater computer skills and experience tend to demonstrate higher intentions to pirate materials using computers (Sims et al. 1996). The greater an individual's perception of control and ability in the Internet piracy situation, the more likely he/she will be to actually commit the behavior. Therefore, the following hypothesis is posited:

Hypothesis 7: Individuals with higher levels of perceived behavior control will demonstrate greater intentions for participating in Internet piracy.

\section{Perceived prosecution risk}

PPR is the degree to which one perceives potential negative outcomes from certain behaviors. This factor is considered to influence one's intention to pirate music (Chiou et al. 2005) and software (Tan 2002). Specifically, Tan (2002) tested the effects of PPR on attitudes toward an engagement in software piracy and found that PPR, along with financial performance and social risks, is a key risk factor applicable to software piracy cases. Like other studies, this study proposed that PPR influences one's intention to engage in Internet piracy. Therefore, the following hypothesis is proposed:

Hypothesis 8: Individuals who perceive high levels of prosecution risk will demonstrate less intention of participating in Internet piracy.

Attitudes and behavioral intention

The attitude toward one's intention is the degree to which one has a favorable or unfavorable evaluation of performing the behavior in question. Both TRA and TPB postulate that an individual's attitude toward a particular behavior is a key predictor of his/her intention to engage in that behavior (Ajzen 1985; Ajzen and Fishbein 1977). The relationship between attitude and behavioral intention has been popularly tested and confirmed in social science research (e.g., Bearden and Woodside 1978; Cronan and Al-Rafee 2008; Leonard et al. 2004). A group of scholars examining software piracy applied the proposition that attitude toward software piracy is a key determinant of intentions to commit software piracy (Peace et al. 2003; Rahim et al. 2000, 2001; Simpson et al. 1994; Wong et al. 1990). For example, Wong et al. (1990) tested this relationship and found that students who used more pirated software also tended to display more positive attitudes toward software piracy, especially in cases where they did not use the software to make money or did not encounter any difficulties in accessing the software. Another software piracy study (Peace et al. 2003) suggested that an individual's attitude toward software piracy was the most essential predictor of one's intentions to pirate software. Based on the findings and proposition of these previous studies, it is reasonable to assume that one's attitude toward Internet piracy is likely to affect his/her intentions of performing such piracy. Accordingly, the following hypothesis is posited:

Hypothesis 9: An individual's attitude toward Internet piracy will positively influence his/her intention of participating in Internet piracy. 
Figure 1 presents the proposed research model this study intends to investigate. In the proposed model, the aforementioned four factors-gender, subjective norms, perceived behavior control, and perceived prosecution risk - are employed as exogenous variables, while attitude and moral obligation act as mediators between exogenous variables and piracy intention.

\section{Research methods}

Data collection

This study employed a self-administered survey for data collection. Respondents included undergraduate and graduate students enrolled in three large universities in Seoul, South Korea. College students were specifically chosen as the sample for this study because a high proportion of college students have been found to be involved in Internet piracy due to the combined factors of their financial status and strong computer skills (Liang and Yan 2005; Sims et al. 1996).

The original sample consisted of 451 college students. In the process of data mining, 73 incomplete responses were removed, resulting in a final study sample of 378 for analysis. The sample was comprised of 197 female (52\%) and 181 male respondents $(48 \%)$ with an average age of 22 years old.

\section{Measurement}

To test the proposed hypotheses, attitude (for H2, H3, H4), behavioral intention (for H5, H6, H7, H8, H9), and moral obligation (for H1; however, for H3 and H9, this variable was used as independent variable) served as dependent variables. A sevenpoint Likert scale ranging from "strongly disagree (1)" to "strongly agree (7)" was employed to measure all variables with the exception of gender.

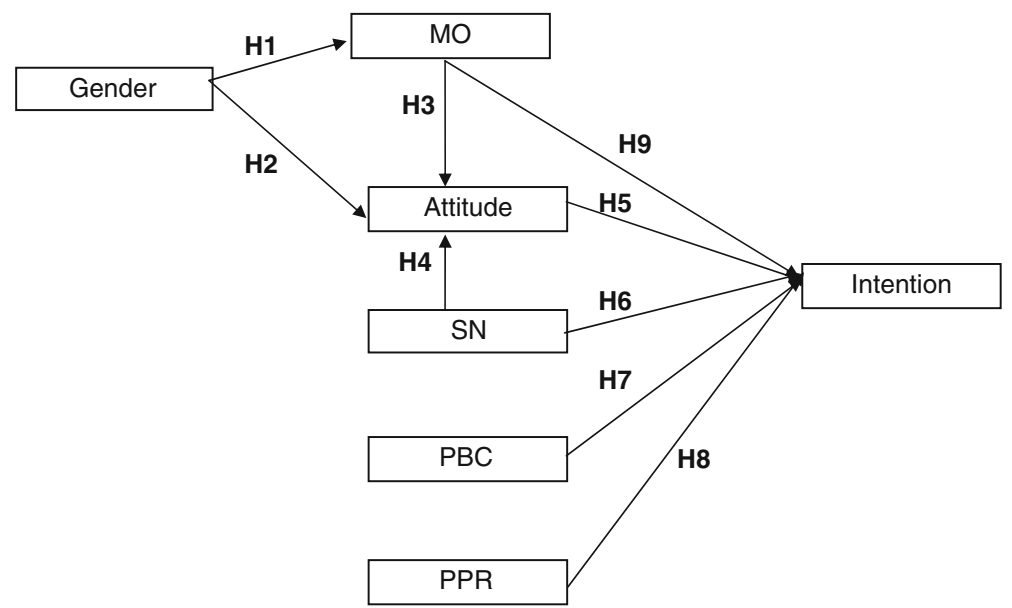

Fig. 1 Proposed research model. $M O$ moral obligation, $S N$ subjective norms, $P B C$ perceived behavior control, $P P R$ perceived prosecution risks 
Gender Participants were asked to indicate their gender. For data analysis purposes, this variable was coded as a dummy variable with " 0 " used for "male" and " 1 " for "female."

Moral obligation This variable relates to one's feelings of guilt or obligation to perform or not to perform Internet piracy, and it was treated as an independent variable for $\mathrm{H} 3$ and $\mathrm{H} 9$ and as a dependent variable for $\mathrm{H} 1$. Participants were asked to respond to three statements, such as "Internet piracy goes against my principles" and "It would be morally wrong to pirate materials on the Internet." Cronbach's alpha for the initial measures of moral obligation was found to be 0.56 .

Subjective norms This study defines subjective norms as one's perceptions of social pressure to perform or not perform Internet piracy (Ajzen 1985). Participants were asked to indicate what kind of opinions they believed their significant others held regarding Internet piracy as well as their personal desires to adhere to how these significant others would like for them to behave. Three items were used to measure subjective norms, including statements such as "Most people who are important to me think I should not pirate material on the Internet" and "When considering Internet piracy, I wish to do what people who are important to me would like me to do." Cronbach's alpha for the initial measures of subjective norms was calculated at 0.71 .

Perceived behavior control This study refers perceived behavior control as an individual's perception of his/her ability and opportunity to commit Internet piracy. Participants were asked to indicate their perceived resources, abilities, or opportunities for committing Internet piracy by considering five statements, including "If I wanted to, I could easily pirate material on the Internet," "I believe that I have the ability to pirate material on the Internet," and "I have the resources necessary to pirate material on the Internet." Cronbach's alpha for the initial measures of this variable was 0.95 .

Perceived prosecution risk This study defines PPR as the degree to which one perceives potentially negative outcomes as a result of performing Internet piracy. This variable was measured by asking participants to respond to the following two statements: "By law, Internet piracy is illegal and will be punished" and "Internet piracy will be caught for copyright infringement." Cronbach's alpha for the initial measures of perceived prosecution risk was 0.93 .

Attitude toward Internet piracy This variable was assessed with items eliciting respondents' overall favorable or unfavorable attitudes toward Internet piracy behavior. In particular, participants were asked to respond to four semantic differential items including favorable/unfavorable, beneficial/harmful, wise/foolish, and good/ bad along a seven-point Likert scale $(1=$ strongly disagree, $7=$ strongly agree $)$. Cronbach's alpha for the initial measure of attitude was 0.80 .

Intention toward Internet piracy This variable was measured by asking participants to respond to three statements, including "I intend to pirate material on the Internet in 
the near future" and "I will try to pirate material on the Internet in the near future." Cronbach's alpha for the initial measures of intentions was 0.97 .

While no universal criteria exists for testing the reliability of measurement scales, one of the most widely accepted rules of thumb is that a scale's alpha should be at least 0.70 to demonstrate internal consistency (Nunnally 1978). ${ }^{3}$ Thus, with the exception of moral obligation, all of the initial measures met this criterion.

\section{Statistical analysis}

Exploratory factor analysis Prior to testing the proposed model, scale purification was conducted through exploratory factor analysis (EFA). EFA established a preliminary version of all measures by identifying items with low factor loadings and determining whether each measurement loaded on its intended factor. The major purpose of this step was to evaluate the dimensionality and the appropriateness of the measurement items for each variable. A measurement item was excluded if it (1) was extracted as the second factor of the intended factor, (2) displayed opposite signs of factor loading coefficients among the other items in the intended factors, and (3) had factor loading values of less than 0.65 with other items of the respective subscale (Hair et al. 1998).

Regression analysis To test the nine hypotheses, this study performed two types of statistical analyses - regression analysis and path analysis. Two multiple regression analyses were used to test all of the hypotheses with the exception of H1. Specifically, the effects of gender, moral obligation, and subjective norms on attitude toward Internet piracy were tested simultaneously through the first regression analysis (hypotheses 2, 3, and 5). The second regression analysis tested the effects of moral obligation, subjective norms, perceived behavior control, perceived prosecution risk, and attitude on piracy intention (hypotheses 4, 6, 7, 8, and 9).

Therefore, the regression models were defined as follows:

$$
\begin{gathered}
\text { Attitude toward the Internet piracy }=\alpha_{1}+\beta_{1} \text { Gender }+\beta_{2} \text { Moral Obligation } \\
+\beta_{3} \text { Subjective norms } \\
\begin{aligned}
\text { Internet Piracy Intention }= & \alpha_{2}+\beta_{4} \text { Moral Obligation }+\beta_{5} \text { Subjective norms } \\
& +\beta_{6} \text { Perceived Behavior Control }+\beta_{7} \text { Perceived } \\
& \text { Prosecution Risk }+\beta_{8} \text { Attitude }
\end{aligned}
\end{gathered}
$$

Path analysis Although regression analysis is commonly used to test the effect of multiple independent variables on a dependent variable and displays easily understandable results, such analysis does pose some drawbacks. First, regression analysis cannot test the endogeneity of mediating variables. For example, hypotheses 2, 3, and 5 aimed to test the relationship between mediating variables, so this study performed path analysis, an extension of the regression analysis (Hair et al. 1998). Second, though regression analysis possesses a function to display the degree of multicolinearity among the independent variables, it cannot manage the issue. Path analysis

\footnotetext{
${ }^{3}$ It has been recommended that a Cronbach coefficient alpha of about 0.90 or above is excellent, around 0.80 is very good, and around 0.70 is adequate (Hair et al. 1998; Kline 2005).
} 
may offer a viable option to control for this problem as it can test interdependent relationships among independent variables. To test the proposed hypotheses in one model, this study used a goodness-of-fit test from the structural equation modeling program AMOS 7, which computes multiple alternatives of goodness-of-fit coefficients. The goodness of fit was calculated by entering the path model and its data into the software package. In summary, the use of multiple statistical analyses increased the anticipated robustness of this study's results.

\section{Results}

\section{Descriptive statistics}

The descriptive statistics demonstrated interesting insight into the variation of data and the means and standard deviation of the respective variables. For the averages of attitude toward the Internet piracy and Internet piracy intention, the dependent variables were $4.54(\mathrm{SD}=1.24)$ and $4.42(\mathrm{SD}=1.81)$, respectively, along the sevenpoint scale. Among the variables used in this study, respondents demonstrated the highest mean score for perceived behavioral control $(M=4.82, \mathrm{SD}=1.54)$. This indicates that respondents seem to believe that they possess ability or control in the context of Internet piracy situations. The respondents tended to perceive lower levels of social pressure against engaging in Internet piracy and moderate levels of moral obligation and perceived prosecution risk $(M=2.91,3.89$, and 3.68, respectively).

\section{Exploratory factor analysis}

The variables with multiple items (three items for behavioral intention, four items for attitude, three items for subjective norms, five items for perceived behavior control, three items for moral obligation, and two items for perceived prosecution risk) were analyzed. The results of EFA indicated that none of the measurement items needed to be removed. Therefore, all initial measures were used to run further statistical analysis. This study used composite scores produced from principal component analysis for each latent variable with multiple measurement items.

\section{Correlation analysis}

Prior to conducting the regression analyses, this study ran a correlation analysis. As shown in Table 1, two of the three suggested variables-moral obligation and subjective norms - were determined to be significantly associated with respondents' attitudes toward the Internet piracy. The five suggested variables - moral obligation, subjective norms, perceived behavior control, perceived prosecution risk, and attitudewere significantly related to Internet piracy intention. In addition, all of the directions demonstrated the same signs as predicted by the hypotheses. However, gender was not found to be associated with either moral obligation or attitude. The correlation analysis indicated that a majority of the suggested independent variables were significantly associated with either attitude or piracy intention, as the hypotheses predicted. Most 
Table 1 Correlation matrix

\begin{tabular}{|c|c|c|c|c|c|c|c|}
\hline & 1 & 2 & 3 & 4 & 5 & 6 & 7 \\
\hline 1. Intention & - & & & & & & \\
\hline 2. Attitude & $0.52 * *$ & - & & & & & \\
\hline 3. $\mathrm{PBC}$ & $0.52 * *$ & $0.32 * *$ & - & & & & \\
\hline 4. $\mathrm{SN}$ & $-0.28 * *$ & $-0.38 * *$ & $-0.24 * *$ & - & & & \\
\hline 5. MO & $-0.35^{* *}$ & $-0.51 * *$ & $-0.21 * *$ & $0.32 * *$ & - & & \\
\hline 6. PPR & $-0.24 * *$ & $-0.51^{* *}$ & $-0.17^{* *}$ & $0.24 * *$ & $0.48 * *$ & - & \\
\hline 7. Gender & $-0.14 * *$ & -0.06 & $-0.16^{* *}$ & 0.01 & 0.01 & 0.05 & - \\
\hline
\end{tabular}

$M O$ moral obligation, $S N$ subjective norms, $P B C$ perceived behavior control, $P P R$ perceived prosecution risks

$* * * p<.001 ; * * p<.05 ; * p<.01$

of the suggested independent variables passed the first criterion and were therefore included in the regression analysis.

\section{Regression analyses}

Table 2 illustrates the outcomes of the regression analyses. In terms of the first regression model that included attitude as a dependent variable, the total variance explained was $30 \%$, and the model was highly significant in terms of $F$ values $(F=$ 53.742, $p=0.000)$. Among the three independent variables tested by regression analysis, moral obligation $(\beta=-0.42, p=0.000)$ and subjective norm $(\beta=-0.25, p=$ 0.000 ) were found to be significant predictors of respondents' attitudes toward Internet piracy. However, gender was not found to be significant. Therefore, the results of the first regression analysis supported hypothesis 3, which predicted that moral obligation is negatively related to attitude, and hypothesis 5, which anticipated that subjective norms would negatively affect attitude. However, the outcome of this regression analysis rejected hypothesis 2 , which predicted that females would display more negative attitudes toward Internet piracy than males.

Table 2 Regression analyses

Numbers outside parentheses indicate standardized $\beta$ - not significant $* * * p<.001$; $* * p<.05 ; * p<.01$

\begin{tabular}{lcc}
\hline \multirow{2}{*}{ Independent variables } & \multicolumn{2}{l}{ Dependent variables } \\
\cline { 2 - 3 } & Attitude & Intention \\
\hline MO & $-0.42^{* * *}$ & $-0.10^{* *}$ \\
SN & $-0.25 * * *$ & - \\
PBC & & $0.37 * * *$ \\
PPR & & - \\
Attitude & & $0.36^{* * * *}$ \\
Gender & - & - \\
$F$ & $53.742 * * *$ & $42.881^{* * *}$ \\
$R^{2}$ & 0.31 & 0.42 \\
Adjusted $R^{2}$ & 0.30 & 0.41 \\
\hline
\end{tabular}


The second regression analysis was performed with Internet piracy intention as a dependent variable. The total variance accounted for was $41 \%$, and this model was highly significant in terms of $F$ values $(F=42.881, p<.001)$. Among the five independent variables tested, moral obligation $(\beta=-0.10, p<0.05)$, perceived behavior control $(\beta=0.37, p<.001)$, and attitude $(\beta=0.36, p<.001)$ appeared to be important precursors of Internet piracy intention. However, subjective norms and perceived prosecution risk were not found to be significant. The outcome of the second regression analysis supported hypothesis 4 , which anticipated that moral obligation would negatively affect Internet piracy intention; hypothesis 7, which predicted that perceived behavior control would be positively related to Internet piracy intention; and hypothesis 9, which expected a positive relationship between attitude toward Internet piracy and Internet piracy intention. However, the results of the second regression analysis rejected hypothesis 6 , which predicted the relationship between subjective norms and Internet piracy intention, and hypothesis 8, which anticipated the relationship between perceived prosecution risk and Internet piracy intention.

\section{Path analysis}

This study proposed nine hypotheses to explore factors affecting three dependent variables - moral obligation, attitude toward Internet piracy, and Internet piracy intention. Path analysis was employed to test all the proposed hypotheses in one integrated model. Table 3 displays the results of path model analysis for the relationship between each variable used in this study, providing the results of the statistical tests for the individual paths, including the magnitude and significance of the model's coefficient.

The effects of the independent variables on attitude toward Internet piracy and Internet piracy intention were tested together with the interdependent relationship between gender, moral obligation, and attitude. A path analysis with maximum

Table 3 Path analysis of proposed research model

\begin{tabular}{lccll}
\hline Path & Standardized coefficient & Standardized error & Hypotheses \\
\hline Gender $\rightarrow$ MO & 0.40 & 0.09 & HP1 & Not supported \\
Gender $\rightarrow$ Attitude & 0.06 & 0.09 & HP2 & Not supported \\
$\mathrm{MO} \rightarrow$ Attitude & $-0.42^{* * *}$ & 0.05 & HP3 & Supported \\
$\mathrm{SN} \rightarrow$ Attitude & $-0.26^{* * *}$ & 0.05 & HP4 & Supported \\
$\mathrm{Attitude} \rightarrow$ Intention & $0.36^{* * *}$ & 0.05 & HP5 & Supported \\
$\mathrm{SN} \rightarrow$ Intention & -0.04 & 0.04 & HP6 & Not supported \\
$\mathrm{PBC} \rightarrow$ Intention & $0.38^{* * *}$ & 0.05 & HP7 & Supported \\
$\mathrm{PPR} \rightarrow$ Intention & 0.07 & 0.05 & HP8 & Not supported \\
$\mathrm{MO} \rightarrow$ Intention & $-0.10^{* * *}$ & 0.05 & HP9 & Supported \\
\hline
\end{tabular}

$* * * p<.001 ; * * p<.05 ; * p<.01$

$M O$ moral obligation, $S N$ subjective norms, $P B C$ perceived behavior control, $P P R$ perceived prosecution risks 
likelihood estimation showed that attitude was affected by moral obligation (H3) $(\beta=-0.42, p<.001)$ and subjective norms (H5) $(\beta=-0.26, p<.001)$. This result indicated that individuals with higher levels of moral obligations tend to demonstrate more negative attitudes toward Internet piracy (H3). Regarding H5, the findings demonstrated that an individual's attitude toward Internet piracy is likely to be influenced by significant others or social pressure. In other words, when an individual feels greater social pressure not to engage in Internet piracy behavior, s/he would also be more likely to demonstrate negative attitudes toward such behavior. This outcome demonstrates good fit with the results of the regression analysis because the same independent variables were determined to be significant in both analyses. Thus, hypotheses 3 and 5 were supported. On the other hand, gender did not display a significant direct relationship to either moral obligation or attitude toward Internet piracy. Therefore, hypotheses 1 and 2 were rejected in the path analysis.

The same analysis displayed that Internet piracy intention was affected by moral obligation (H4) $(\beta=-0.10, p<0.05)$, perceived behavior control (H7) $(\beta=0.38$, $p<.001)$, and attitude (H9) $(\beta=0.36, p<.001)$. Results supported hypothesis 4 , thus indicating that an individual demonstrating higher level of moral obligation tends to exhibit less intention to participate in Internet piracy. Regarding H7, the finding suggested that individuals with greater perceived behavior control were more likely to display greater intentions to partake in Internet piracy. Also, as expected, attitude toward Internet piracy was found to be a determinant of Internet piracy intention. Therefore, hypotheses 4, 7, and 9 were supported. On the other hand, neither subjective norms nor perceived prosecution risk were found to be significant predictors of Internet piracy intention. Therefore, hypotheses 6 and 8 were rejected in both analyses.

Figure 2 displays the results of the path model, and Table 4 indicates that the fit of the path model was generally satisfactory according to the given fit indices. The

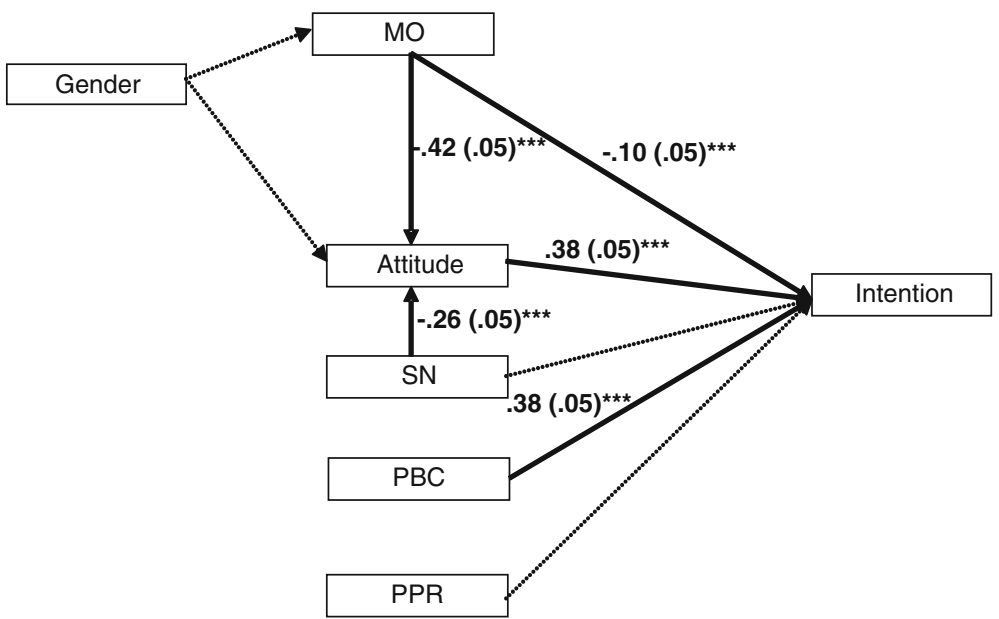

Fig. 2 Tested model. Dotted lines indicate non-significant paths. Solid lines indicate significant paths. The numbers outside parentheses indicate standardized coefficient and those in parentheses indicate standardized error. $*^{*} p<.001 ;{ }^{*} p<.05 ;{ }^{*} p<.01$. $M O$ moral obligation, $S N$ subjective norms, $P B C$ perceived behavior control, $P P R$ perceived prosecution risks 
Table 4 Goodness-of-fit indices: the proposed model

\begin{tabular}{lll}
\hline Model fit & Criteria & \\
\hline Chi-square/ $(d f)$ & $\leq 5$ & 6.80 \\
Comparative fit index & $\geq 0.90$ & 0.93 \\
Goodness-of-fit index & $\geq 0.90$ & 0.96 \\
Normed fit index & $\geq 0.90$ & 0.92 \\
Root mean squared error residual & $\leq 0.08$ & 0.13
\end{tabular}

overall fit results for the model were $\mathrm{CFI}=0.93$, GFI $=0.96$, and $\mathrm{NFI}=0.92$, with all exceeding the recommended 0.90 threshold level (Hoyle and Pantera 1995).

\section{Discussions and conclusions}

This study provides greater understanding and insights into the influential predictors of attitudes toward Internet piracy as well as intentions of participating in Internet piracy among South Korean college students. The two main analyses, regression and path, produced both interesting and consistent results. The results demonstrated that moral obligations and subjective norms are significant predictors of an individual's attitude toward Internet piracy. Moreover, three factors - moral obligation, perceived behavioral control, and attitude - are essential antecedents of an individual's intention to engage in Internet piracy. Figure 2 represents the outcome of the model tested in this study. The results of this study embrace multiple implications for factors affecting piracy and promote future research around this topic.

In examining moral obligation as a predictor of attitude and intention toward Internet piracy, the findings suggested that an individual's moral obligation acts as an important antecedent of his/her attitudes and intentions toward Internet piracy. The notion of moral obligations maintains that individuals experience personal feelings of guilt that can influence their attitudes and intentions toward Internet piracy. These feelings of guilt likely play a role in forming individuals' attitudes, which tend to transform into behavioral intentions. For example, this finding can be utilized as a method to deter Internet piracy by underscoring the threat of undesirable consequences through a variety of campaign messages. It is therefore assumed that individuals exposed often to such messages would be more likely to demonstrate unfavorable attitudes toward Internet piracy. Moreover, they would be more likely to feel guilty if they attempted to pirate materials on the Internet.

Subjective norms represent an important notion when predicting attitudes toward Internet piracy. It is logical to assume that reference groups that students perceive as important in their daily routines, including parents, friends or teachers, play an influential role in their formation of attitudes toward Internet piracy. In other words, these influential people may represent the "social pressure" necessary to cultivate either positive or negative attitudes toward Internet piracy among the students. Accordingly, this research suggests targeting these important reference groups when planning a campaign strategy or creating a persuasive message against Internet piracy. Role models, such as parents in the home or teachers in the schools, could represent a good starting point for effectively instilling negative attitudes toward Internet piracy in students. 
Unlike in previous studies (Chang 1998; Cronan and Al-Rafee 2008), however, the subjective norm was not found to be an important predictor of piracy intention. This counterintuitive finding demonstrates that people are likely to construct negative attitudes toward Internet piracy when they are aware of reference groups' perceptions that they should not engage in piracy; however, such awareness is unnecessary in preventing these individuals from attenuating intention toward piracy or eventually partaking in pirating behavior. Considering that many studies have found attitude to be the best predictor of an intention to partake in a specific behavior (Al-Rafee and Cronan 2006), which was further confirmed by the outcome of the path analysis, this study can concede that there may be an indirect effect of the subjective norms on piracy intention via attitude. Also, subjective norms alone represent a scant factor in deterring piracy behavior in the Korean context. Consequently, this hypothesis should be addressed in future research, which could yield interesting and informative results.

Perceived behavior control was found to be a significant predictor of piracy intention among Korean students. Perceived behavior control refers to an individual's perception of his/her ability and opportunity to engage in the behavior (Ajzen 1991). This is an important factor to consider in the context of South Korea, which furnishes the world's fastest Internet connections and plans to connect every home to the Internet at one gigabit per second, or more than 200 times the average household setup speed in the USA (McDonald 2011). The infrastructure of Internet service can provide Korean students ample opportunities for involvement in Internet piracy, and they seem to perceive Internet piracy activity to be a relatively easy process in the context of the given system. Moreover, Korean students appear well aware of their abilities and available resources for committing Internet piracy.

As mentioned earlier, many studies have found attitude to be the most significant predictor affecting behavioral intention (Trafimow and Sheeran 1998), and the findings of this study further support the idea that attitude toward Internet piracy is closely associated with individuals' intentions of engaging in Internet piracy. Attitude has been vigorously studied since individual attitude is considered an important construct in predicting one's behavioral intention (Al-Rafee and Cronan 2006), which in turn has been found to be an accurate variable for predicting behavior (Ajzen 1985). In certain conditions where subjective norms operate or an individual is ambivalent about a certain issue, however, attitudes are less likely to translate into actual behavior (Perloff 2003). Thus, significant antecedents of attitude, such as subjective norms or moral obligation, tend to be factors more concerned with creating persuasive messages against the piracy.

A couple of this study's observations are noteworthy. First, perceived prosecution risk was not found to be significant in predicting attitudes or intentions toward Internet piracy, a finding that differs from those of previous studies (Tan 2002). This finding suggests that Korean students are less sensitive to the negative consequences of copying illegal materials on the Internet. Woo's (2003) study argued that although a digital copyright case on file-sharing service strives for controlling Internet piracy more strictly, the case demonstrated a limited influence on Koreans in altering their perceptions of piracy. Along with the public campaign against piracy, more press release activities regarding copyright infringements and cases are therefore encouraged in order to increase awareness of the prosecution of Internet pirates, especially in Korea.

Second, the findings indicate that gender is not considered a significant antecedent of either moral obligation or attitude in South Korea. As discussed earlier, there have 
been mixed findings regarding the significance of the individual attribute on piracy or immoral behaviors. In some studies, findings have shown that females tend to be more sensitive than males to unethical behaviors (Leonard and Cronan 2001; Reiss and Mitra 1998), while others have reported that gender does little to explain immoral behaviors (Taylor and Shim 1993; Wong et al. 1990). The results of this study are in line with the latter perspectives, but further examination of this variable is encouraged in future studies, as it is unclear whether this study's finding is limited to the Korean local context or is generalizable as a universal norm.

\section{Limitations and future research directions}

As is true with much research, this study has several limitations that should be considered in helping to inform future research endeavors. Several of this study's findings are considered original and compelling, but they should be interpreted with caution. First, a non-probability sampling method was used to collect the sample. Although the study offered rationales for selecting college students as the sample, the findings of this research may therefore lack generalizability. Thus, more research is required to validate the proposed model. Second, this study is limited to a local context to determine factors affecting attitudes or intentions toward Internet piracy. Future studies are encouraged to include multiple countries in efforts to compare this study's results with those found in different cultural contexts. Such multi-country studies would contribute to identification of a universal measurement scale.

\section{References}

Ajzen, I. (1985). From intentions to actions: A theory of planned behavior. In J. Kuhl \& J. Beckman (Eds.), Action-Control: From Cognition to Behavior (pp. 11-39). Heidelberg: Springer.

Ajzen, I. (1991). The theory of planned behavior. Organizational Behavior and Human Decision Processes, $50,179-211$.

Ajzen, I., \& Fishbein, M. (1977). Attitude-behavior relation: A theoretical analysis and review of empirical research. Psychological Bulletin, 84, 888-918.

Al-Rafee, S., \& Cronan, T. P. (2006). Digital piracy: Factors that influence attitude toward behavior. Journal of Business Ethics, 63(3), 237-259.

Ang, A. Y., Lo B. W. N. (1998). Software piracy attitudes of tertiary students in Australia. In Electronic proceedings of the South East Asian Computer Conference, Darwin, Australia.

Banerjee, D., \& Cronan, T. P. (1998). Modeling IT ethics: A study in situational ethics. MIS Quarterly, 22 (1), 31-60.

Bearden, W. O., \& Woodside, A. G. (1978). Situational and extended attitude models as predictors of marijuana intentions and reported behavior. Journal of Social Psychology, 106(1), 57-67.

Beck, L., \& Ajzen, I. (1991). Predicting dishonest actions using the theory of planned behavior. Journal of Research in Personality, 25, 285-301.

Bommer, M., \& Gratto, C. (1987). A behavioral model of ethical and unethical decision making. Journal of Business Ethics, 6(4), 265-280.

Business Software Alliance. (2010). Piracy impact study: The economic benefits of reducing software piracy. Retrieved March 18, 2010, from http://portal.bsa.org/piracyimpact2010/index.html.

Chang, M. (1998). Predicting unethical behavior: A comparison of the theory of reasoned action and the theory of planned behavior. Journal of Business Ethics, 17, 1825-1834.

Chiou, J.-S., Huang, C.-Y., \& Lee, H.-H. (2005). The antecedents of music piracy attitudes and intentions. Journal of Business Ethics, 57, 161-174. 
Conner, M., \& Armitage, C. J. (1998). Extending the theory of planned behavior: A review and avenues for future research. Journal of Applied Social Psychology, 28(15), 1429-1464.

Cronan, T. P., \& Al-Rafee, S. (2008). Factors that influence the intention to pirate software and media. Journal of Business of Ethics, 78, 527-545.

Ford, R., \& Richardson, W. (1994). Ethical decision making: A review of the empirical literature. Journal of Business Ethics, 13, 205.

Grasmick, H. G., \& Scott, W. J. (1982). Tax evasion and mechanisms of social control: A comparison with grand and petty theft. Journal of Economic Psychology, 2(3), 213-230.

Hair, J. F., Jr., Anderson, R. E., Tatham, R. L., \& Black, W. C. (1998). Multivariate data analysis (5th ed.). Upper Saddle River: Prentice Hall.

Hoyle, R. H., \& Pantera, A. T. (1995). Writing about structural equation models. In R. H. Hoyle (Ed.), Structural equation modeling: Concepts, issues, and applications (pp. 158-176). Thousand Oaks: Sage.

IFPI06. (2006). IFPI06: Digital music report. Retrieved March 17, 2011, from http://www.ifpi.org/content/ library/digital-music-report-2006.pdf.

Internet World Stats. (2010). Top 58 countries with the highest Internet penetration rate. Extracted on March 16, 2010 from http://www.internetworldstats.com/top25.htm.

Jones, T. (1991). Ethical decision making by individuals in organizations: An issue contingent model. The Academy of Management Journal, 16(2), 366-395.

Ki, E.-J., Chang, B.-H., \& Khang, H. (2006). Exploring influential factors on music piracy across countries. Journal of Communication, 56, 406-426.

Kline, R. B. (2005). Principle and practice of structural equation modeling. New York: Guilford.

Kreie, J., \& Cronan, T. P. (1999). Copyright, piracy, privacy, and security issues: Acceptable or unacceptable actions for end users. Journal of End User Computing, 11(2), 13-21.

Leonard, L., Cronan, T. P. (2001). Illegal, inappropriate, and unethical behavior in an information technology contexts: A study to explain influence. Journal of the Association for Information Systems, 1 , Article 12.

Leonard, L. N. K., Cronan, T. P., \& Kreie, J. (2004). What influences IT ethical behavior intentions-planned behavior, reasoned action, perceived importance, or individual characteristics? Information Management, 42(1), 143-158.

Liang, Z., \& Yan, Z. (2005). Software piracy among college students: A comprehensive review of contributing factors, underlying processes, and tackling strategies. Journal of Educational Computing Research, 33(2), 115-140.

McDonald, M. (2011). Home Internet may get even faster in South Korea. New York Times. Retrieved on March 7, 2011 from http://www.nytimes.com/2011/02/22/technology/22iht-broadband22.html.

Motion Pictures Association of America (2005). Piracy report. Retrieved March 25, 2008 from http://www.mpaa.org/piracy_internet.asp.

Nunnally, J. C. (1978). Psychometric theory. New York: McGraw-Hill.

Parker, D., Manstead, A. S. R., Stradling, S. G., Reason, J. T., \& Baxter, J. S. (1992). Intention to commit driving violations: An application of the theory of planned behavior. Journal of Applied Psychology, 77 (1), 94-101.

Peace, A. G., Galletta, D. F., \& Thong, J. Y. L. (2003). Software piracy in the workplace: A model and empirical test. Journal of Management Information Systems, 20(1), 153-177.

Pereira, L. B., \& Kanekar, S. (1994). Perceptions of initiatory and retaliatory cheating behaviour. Indian Psychologist, 3(1), 17-20.

Perloff, R. M. (2003). The dynamics of persuasion: Communication and attitudes in the 21st century (2nd ed.). Mahwah: LEA.

Rahim, M. M., Rahman, M. N., \& Seyal, A. H. (2000). Softlifting intention of students in academia: A normative model. Malaysian Journal of Computer Science, 13(1), 48-55.

Rahim, M. M., Seyal, A. H., \& Rahim, M. N. (2001). Factors affecting softlifting intention of computing students: An empirical study. Journal of Educational Computing Research, 24(4), 385-405.

Reiss, M., \& Mitra, K. (1998). The effects of individual difference factors on the acceptability of ethical and unethical workplace behaviors. Journal of Business Ethics, 17(14), 1581-1593.

Rest, J. R. (1979). Developing in judging moral issues. Minneapolis: University of Minnesota Press.

Simpson, P. M., Banerjee, D., \& Simpson, C. L. (1994). Softlifting: A model of motivating factors. Journal of Business Ethics, 13, 431-438.

Sims, R. R., Cheng, H. K., \& Teegen, H. (1996). Toward a profile of student software piraters. Journal of Business Ethics, 15, 839-849.

Swinyard, W. R., Rinne, H., \& Kau, A. K. (1990). The morality of software piracy: A cross-cultural analysis. Journal of Business Ethics, 9, 655-664. 
Tan, B. (2002). Understanding consumer ethical decision making with respect to purchase of pirated software. Journal of Consumer Marketing, 10(2), 96-111.

Taylor, G. S., \& Shim, J. P. (1993). A comparative examination of attitude toward software piracy among business professors and executives. Human Relations, 46(4), 419-433.

Trafimow, D., \& Sheeran, P. (1998). Some tests of the distinction between cognitive and affective beliefs. Journal of Experimental Social Psychology, 34, 378-397.

United States Trade Representative. (2010). 2010 special 301 report. Washington, D.C.: United States Trade Representative.

Vallerand, R. J., \& Pelletier, L. G. (1992). Ajzen and Fishbein's theory of reasoned action as applied to moral behavior: A confirmatory analysis. Journal of Personality and Social Psychology, 62, 98.

Williams, S. W., Ogletree, S. M., Woodburne, W., \& Raffeld, P. (1994). Gender roles, computer attitudes and dyadic computer interaction: Performance in college students. A Journal of Research, 5(3), 515526.

Wong, G., Kong, A., \& Ngai, S. (1990). A study of unauthorised software copying among post-secondary students in Hong Kong. Australian Computer Journal, 22(4), 114-122.

Woo, J. (2003). The limited significance of the legal framework of digital copyright: Focusing on the consciousness and activities of P2P file-sharing users. Korean Journal of Journalism and Communication Studies, 47(1), 81-113. 